\title{
Tell and Write, the Effect of Storytelling Strategy for Developing Story Writing Skills among Grade Seven Learners
}

\author{
Fatma Alkaaf, Ali Al-Bulushi \\ Curriculum and Instruction Department, Sultan Qaboos University, Muscat, Oman \\ Email: alkaaf@squ.edu.om, aha109@squ.edu.om
}

How to cite this paper: Alkaaf, F. and Al-Bulushi, A. (2017). Tell and Write, the Effect of Storytelling Strategy for Developing Story Writing Skills among Grade Seven Learners. Open Journal of Modern Linguistics, 7, 119-141. https://doi.org/10.4236/ojml.2017.72010

Received: February 8, 2017

Accepted: April 17, 2017

Published: April 20, 2017

Copyright ( $) 2017$ by authors and Scientific Research Publishing Inc. This work is licensed under the Creative Commons Attribution International License (CC BY 4.0).

http://creativecommons.org/licenses/by/4.0/ (c) (†) Open Access

\begin{abstract}
This study investigates the effect of storytelling as a strategy for developing story writing skills among grade seven pupils in a public Omani school. The sample of the study consisted of 243 pupils randomly selected and assigned to experimental and control groups. The data used for the purpose of this study were collected over the course of one semester via pre-post test design for equivalent groups. The experimental groups were taught by using the adopted storytelling strategy, whereas the control groups were taught by using the conventional procedures as prescribed in the formal teacher's guidebook. The researchers assessed the effect of storytelling as a strategy for developing story writing skills and the findings indicated that the experimental group outperformed the control group in the story writing skills test. This was indicative of the fact that the storytelling strategy may have a significant positive effect on pupils' story writing. Important implications of this study within the framework of a similar context are also outlined.
\end{abstract}

\section{Keywords}

Story Writing, Writing Skills, Strategy Teaching, Teaching Arabic

\section{Introduction}

Writing is considered to be one of the most important means of communication through which humans can express their thoughts and discover the thoughts of others. It is considered to be the pride of the human mind, as it is the greatest production of human thinking. Through writing, culture has been recorded and transferred from a generation to another. In addition, through writing, the human being could record the developments around it, how it shapes our lives, and how it influences the society overall (Migawer, 2001). 
Verbal and written communication is vital in order for people to interact with each other. Writing is particularly crucial for humans in order to learn about the thoughts and feelings of others. Effective writing has gained considerable importance and has become an essential tool for teachers and educators in order to ensure that pupils have the required writing skills to be successful in their study (Graham, 2006).

Vygotsky (1978) stated that success in writing is not exclusively dictated by the writer's cognitive skills. As a skill, it is possible for storytelling to utilize the cognitive and affective aspects of learning and offer a pedagogical alternative for developing various language skills. During storytelling pupils enjoy being together and learning about one another's views, receiving immediate responses and writing on topics that interest them (Sisserson, Manning, Kenpler, \& Jolliffe, 2002; Thomas, 2000).

The goals of teaching different types of writing compositions stem from the importance thereof, as they provide interactants with a valuable opportunity to communicate. It is a way to expresses one's ideas and employs various linguistic techniques and expressions. In addition, teaching pupils different types of writing by means of such potential writing strategies could provide pupils with a valuable opportunity to improve their communication skills (Hillocks, 1995; Shahata, 2000). One of the writing genres that language teachers could potentially use is narrative writing which has been empirically researched in several contexts (e.g. Aida, 2007; Gregor, 1998) and showed a strategic relationship with other language skills.

\section{Narrative Writing}

Distafano (2007) defined narrative writing as writing a story to include specific elements that work together in order to stimulate the interest and excitement of the writer and readers. It makes the writer or the reader feel as if they partake in the story or could First, confirm that you have the correct relate to it directly somehow.

The concept of narrative writing is defined as composing a text on the basis of a certain structure in order to describe the events from the writer's point of view according to people's reactions (Charlotte, 2001). This type of writing depicts a story in a special, technical and exciting way, while addressing the feelings of readers or listeners. It is pertinent in novels, personal articles, plays and short stories.

The purpose of narrative writing is to present pupils with the opportunity to express themselves in a personal manner. It is characterized by a creative style which allows them to adapt their creative writing. It reflects the awareness of the pupil about literary works, such as poetry, articles, and stories as, well as their ability to produce a coherent product which expresses their feelings and the manner in which they could impact others. Narrative writing could also help the writer to use linguistic styles and literary forms suitable for the desired topics and consistent with the type of audience. Teachers can help pupils in mastering 
this type of writing by prompting them with some questions about the events of the story, its chronology, their expectations, and moral of the story (Chavis, 2009).

Narrative writing aims to present a story based on personal experiences or imaginative events. According to Sue (2007), the three main elements of narrative stories are:

1) Introduction: the extent to which the writer is capable of outlining the topic and drawing the reader's attention to the elements of the story.

2) Body: the behavioral indicators that construct the plot and weave the events towards the climax in order to eventually discover the moral of the story.

3) Conclusion: the resolution of the story's problem and a statement marking a logical ending.

Stories occupy a prominent position in children's literature. Young readers tend to like and enjoy them whether heard or read. It is the appropriate form through which morals and positive ideas may be presented (Issa, 2007).

The concept behind a story and the significance thereof differ across cultures. For example, in Western cultures stories are referred to as a "series of events which have been ascending to a culmination and then finish by the solution after the gradual decline of events" (Lipman, 1999). However, African cultures consider the story to be constituted by a balanced number of events which are linked by a common general idea driven by multiple characters, with each character having its own story (Lipman, 1999). Moreover, Golden (1984) describes children's perception of stories as being a mental representation of the story structure, or an outline of the basic story elements and their organization. Arabs, on the other hand, see the story as a series of "interrelated events which revolve around a main character and lists action to adapt to that position" (Al-Hadidi, 1996: p. 185). In addition, some would argue that stories are a work of art and a series of interrelated events that revolve around the main idea and include a number of plots and a solution (Hanoora, 1999).

Based on the previous background, story writing (i.e. used interchangeably with narrative writing) is viewed in this study as a literary art focused on displaying a series of logical events executed by one or several characters in order to convey a specific moral. Stories are regarded as a prominent genre and are commonly used in lessons and in life in general. Just how other genres and literary works have their own linguistic requirements (i.e. grammatical structures and language usage), so does writing a story. Storywriters should be mindful of these requirements in order to produce stories on the basis of these characteristics. When well-crafted, such literary works enable writers to express themselves in various idiosyncratic forms and touch peoples' lives.

Spivey (1989), Dinkson (2001) and Pfeiffer and Boles (2008) outlined a number of story writing skills such as:

1) The ability to formulate an appropriate introduction that can excite, attract the reader and link to the essence of the story's main idea. Students can choose the beginning and the description of an event, place, character or an 
exciting plot in the story.

2) The ability to create active roles for the characters in the story. This skill is apparent when choosing suitable characters to match the topic of the story and defining each role in order to conform to the story and reflect its idea.

3) The ability to arrange and organize events according to temporal sequence and interdependence. This skill translates into the narration of the story events in their chronological order using appropriate linkage devices.

4) The ability to build an atmosphere suitable for the course of events of the story. This skill is apparent when establishing the setting of the story and utilizing the time factor in order to serve the course of events.

5) The ability to formulate a problem in relation to the story's idea. This skill is about formulating a problem that requires a solution and is linked to the core structure of the problem.

6) The ability to formulate an appropriate conclusion for the course of events of the story. This skill transpires in providing solutions to the problem of persuasion and associated events.

7) The ability to use visuals in order to obtain a complete story.

8) The ability to use vocabulary items and appealing linguistic expressions in writing. This skill is about the use correct utilization of lexis, expressions and story dialogue.

9) Effective use of linguistic conventions in the story's morphology, grammar, spelling and coherence devices.

10)Effective use of punctuation in writing guided by the meaning of the story.

\section{Relationship between Storytelling and Writing}

The storytelling strategy could be used for the purpose of developing writing since it employs different phases of literacy development. It also variably improves the four essential skills in language learning along with grammar and vocabulary. In contrast, other teaching approaches may instructionally help one of the writing processes, such as the Self-Regulated Strategy Development (SRSD), which is an instructional approach that reinforces independent learning by encouraging students to monitor, evaluate, and revise their writing. However, one of the major limitations of the SRSD is the focus placed on the planning process at the expense of revising (Schnee, 2010).

Effective instructional strategies are important as they allow pupils to become proficient writers. Over time, we have consistently expanded our knowledge of the nature of writing, yet teachers and educationists are still looking for better ways to improve their instructions, particularly in the case of those pupils who have never written a story before.

Gallets (2005) indicated that in storytelling one person relates the story from memory to a different person or a group. The teller acts as a transmitter and the listener(s) as a receiver of thoughts and ideas with interaction between the two. Young children listen to stories and other narratives and subsequently incorporate them in their writing through drafting, sharing, or editing. In this regard, 
Hana (2010) found that storytelling promotes listening skills and listening comprehension, fosters imagination, as well as improves vocabulary usage and writing techniques among pupils and the interaction between pupils and between pupils and teachers. Aida (2007) also indicated that storytelling is particularly effective in terms of improving listening and writing skills among pupils.

Gregor (1998) outlined a number of benefits associated with teaching through the art of storytelling such as exchanging experiences, developing self-confidence in speaking and writing, improving vocabulary and language skills, fostering creativity, enhancing comprehension, and encouraging an ongoing discussion of thoughts and beliefs. Diawn (2008) indicated that storytelling improved pupils' self-confidence in their own writing skills and encouraged cooperation among pupils. Furthermore, Isabell, Sobool, Lindauer, and Lowrance (2004) investigated the corresponding and complementary ways in which storytelling and story reading influence the language development and story comprehension among 3 - 4 year old children. They found that storytelling helped children with speaking, overall comprehension and recognizing the story's elements.

Storytelling also plays an important part in reading and writing classes. Al-Mansour and Al-Shorman (2011) indicated that storytelling improves pupils' reading comprehension and suggested that oral storytelling is useful for improving learners' self-confidence and reading skills. Since stories constitute a form of creative writing, learners should be encouraged to practise it pedagogically and extensively. Birkenkraha (2014) asserted that storytelling supports students in creative writing and helps to improve the quality of learners' compositions. Zabel (1991) and Yang and Wu (2012) mentioned that telling stories in the classroom improved skills such as critical thinking, vocabulary and learning motivation. The educational benefits of storytelling in the classroom, according to (Groce, 2001) include instilling a love of language among students, cultivating imagination, improving both listening skills and vocabulary, consolidating comprehension, recalling the story, and encouraging pupils to adopt critical thinking.

Storytelling could also be utilized in order to promote language usage among children. Egan (1987) stated that storytelling should be used in order to help young children with their language skills. It is possible to make reading and writing meaningful and interactive by using children's oral culture. Meher (1995) formulates a list of ideas that teachers could take into account:

1) The fact that children can relate their experiences through emotions.

2) Storytelling makes lessons enjoyable.

3) Storytelling inspires children and encourages them to achieve fluency.

4) A teacher who is passionate about language is likely to instill the same interest in their students.

Ralston (1993) stated that there was a strong correlation between storytelling and language skills. The aims of both are to help pupils enjoy literature, stimulate their imagination, teach them how to listen and improve their verbal and oral communication skills. Furthermore, storytelling contributes to helping pu- 
pils learn the story's elements and interact with the spoken word (Hillocks, 1995).

The storytelling strategy could improve the Arabic language skills of pupils in areas such as the communication between teachers and pupils, comprehension, fluency, vocabulary, sequencing and creative writing. It might also initiate creative thinking. When pupils become interested in stories, mental images spring to mind and the thought process associated thereto is triggered (Robinson, 2008). In addition, Davis (2000) mentioned that pupils initially discuss a story with their peers before they begin the writing process. The feedback received from other pupils helps the writer to refine and retell his or her story until he or she is ready to write it. This strategy enables writers to prepare for the first stages of the writing process by listening, thinking and speaking.

\section{Storytelling across Some of the World}

Storytelling has long been the mainstay of the global society in terms of communication and storing information. In ancient times, storytelling constituted the way in which people held onto their customs and beliefs and passed on the knowledge they acquired to younger generations. Prior to the earliest historical records, no other means of doing so were available and it is the oldest method we know in which people memorize events (Abrahamson, 1998). Abrahamson (1998) claims that storytelling may have facilitated the survival of some civilizations considering that the experiences of life and death were thus passed on to generations to come. Ruth Sawyer (2011) stated that 4000 BES is the very first record of storytelling that we know of (as cited in Abrahamson, 1998). Back in ancient times, storytellers were very well regarded because they took their craft to a level beyond entertainment. They could often help people to understand religious or cultural matters, or offer comfort in sorrow. They were popular in both Egyptian and Roman cultures and even among nomadic tribes, such as the Gypsies, who found them useful (Douglas, 2005).

For Mello (2001), storytelling in ancient times was used to pass on people's ideas and knowledge. Back then, different societies used it not only in order to exchange ideas and perceptions, but also for the purpose of teaching and learning (Meyer \& Bogdan, 2001). Native American cultures had no written language, and as a result they used oral storytelling in order to exchange information about their values and beliefs (Koki, 1998). They also used it in order to pass on such details to their children (Meyer \& Bogdan, 2001). Native Americans told stories about the meaning of life in order to instill values and encourage a certain type of behavior, to perform rituals and ceremonies, and in the case of respected members of the community, to pass on their knowledge (Koki, 1998).

Asian and European societies also used oral storytelling in a similar way to Native Americans. Topical items such as birth, death and marriage were conveyed by storytellers who travelled between villages in order to propagate such values (ibid.). In some cases, picture writing and drawings complemented oral storytelling. According to Patterson (1999), in Japan drawings and paintings 
were used for the purpose of storytelling. For this reason, storytelling can constitute both a mark of artistic expression and a way to communicate. Storytelling is creative. The teller invents a storyline and relates it to the listener. The listener then creates his or her mental perception on the basis of the teller's construction of the storyline and the relationships between its various elements.

The whole story is told in such a way that enables storytelling to be perceived as a means of communication which can include images, sounds and body movements. This storytelling only happens at a given time and place and does not get replicated in the same way. For this reason, storytelling has to be one of the highest forms of art and communication, which justifies why it is becoming such an exceptional teaching/learning tool. In addition, storytelling could be associated with a number of activities (e.g. representation, drawing, concept maps, narrative and descriptive activities) that could be used to help pupils to understand, adopt, and develop story writing skills.

\section{The Problem}

According to the findings of the First Educational Forum for The Development of Linguistic Performance held on the 6th of April 2009 by the Ministry of Education in Muscat (Ministry of Education, 2009), significant shortcomings could be identified among grade seven pupils in Oman particularly in terms of their story writing skills. Unassessed attempts have been made in order to rectify these shortcomings but the issue still persists. Although it is the native language of the country, there is an increasing concern that the teaching of Arabic in Oman should be improved in order to enhance pupils' written competencies specifically as this limitation has recently become apparent among higher education institutions who receive school graduates. The forum also recommended increasing the number of writing assignments in the Arabic curriculum for grade seven. Furthermore, to the researchers' knowledge, no study has been conducted in Oman in this area for this particular grade.

\section{Significance of the Study}

This study will contribute to the research of the storytelling strategy in the Arabic language and its effect on developing story writing skills for grade seven in Oman and similar grades in similar contexts regionally and elsewhere. It also hopes to:

- create a strong correlation between the language skills, especially storytelling and story writing;

- raise the awareness about the storytelling strategy among Arabic language teachers and possibly encourage them to explore its potential in their classrooms;

- raise the awareness of those involved in designing the Arabic language curricula about the relationship between teaching strategies and the quality of the outputs;

- develop educational narrative materials and use them to teach any of the four 
language skills;

- explore the effect of the storytelling strategy on the development of writing skills in general and story writing in particular.

\section{Method}

\subsection{Research Question}

The present study seeks to answer the following question:

Are there any statistically significant differences among Omani seventh grade pupils at the level of each skill out of the ten story writing skills on the basis of:

- the storytelling strategy

- the type of school (public or private)

- gender (male or female) and

- the interaction among the above-mentioned variables?

\subsection{Design}

The present study adopts a quasi-experimental design, employing pre-post test designs with an experimental group and a control group. Ten groups of grade seven pupils assigned to six schools (two boys' schools and two girls' schools) and two private schools (mixed pupils) were selected as participants in the present study. Three of them formed the experimental group and were taught using the adopted storytelling strategy, whereas the remaining three formed the control group and were taught using the conventional prescribed method, as depicted in the formal teacher's guide.

\subsection{Participants}

The sample of the study consisted of 243 pupils from grade seven in the second cycle of basic education in Salalah city in Oman. They were from four public schools (two boys' schools and two girls' schools) and two private schools (mixed pupils). Each public school had an experimental and a control group over the course of the study, with the exception of private schools. The experimental groups $(\mathrm{N}=120)$ were taught using the adopted storytelling strategy and the control groups $(\mathrm{N}=123)$ were taught using the conventional method prescribed in the formal teacher's guidebook. Due to the availability of only one grade seven in each private school, the study treated a class in private school 1 as a control group, whereas the class in private school 2 was treated as an experimental group.

The researchers provided the teachers involved in the study with a two-week workshop about how to implement the intervention among their learners. The training involved the five teachers who taught the experimental group $(\mathrm{N}=120)$ pupils at the five schools. The storytelling strategy consisted of 18 lessons. Every lesson included the pupils' worksheet and handouts. Five stories in line with the objectives of reading and writing for grade seven were created to cover several themes.

Ethical consent was obtained from all participants prior to the commence- 
ment of data collection. Learners were given the consent form and their guardians submitted it signed later on. Likewise, teachers' consent was ensured before training them using the manual. The confidentiality and anonymity of all participants were ensured throughout data collection and research process.

\subsection{Pre-Post Story Writing Skills Test}

A story writing skills test was constructed in order to assess pupils' story writing capacities before and after the implementation of the storytelling strategy. The pre-test was administered at the beginning of the first semester of the school year, while the post-test was administered at the end of the same semester. Preand post-tests play an essential role in the research design and are very important in order to check the effect of random samples on the selected measure (Robson, 2002). The differences among pupils over the course of the two tests could help in terms of evaluating the effectiveness of the treatment.

Based on the literature, the test was constructed, validated, and included questions that asked the students to:

1) formulate another appropriate introduction to the story.

2) create active roles for the characters in the story.

3) arrange and organize events according to their sequence and interdependence.

4) rewrite the arranged events of the story using coherence conjunctions.

5) build a suitable atmosphere for the course of events of the story (place/time).

6) build another appropriate ending for the story.

7) suggest a new title for the story.

8) describe the pictures in order to finalize the story.

9) use grammar and spelling.

10) use appropriate punctuation.

\subsection{The Storytelling Strategy}

The storytelling strategy could improve the Arabic language skills of pupils in some areas such as comprehension and communication between teachers and pupils. When pupils become interested in stories, mental images spring to mind and the thought process associated thereto is triggered (Robinson, 2008). Davis (2000) indicated that by using stories, pupils talk to their peers who are listening before they initiate the writing process and their feedback to each other helps the writer to refine and retell his or her story, which eventually improves their writing. This strategy is aimed at:

1) Making learners realize that story writing skills are important in achieving the language learning outcomes.

2) Helping both teachers and pupils to recognize the benefits of story writing skills.

3) Improving writing skills in general and story writing skills in particular.

The storytelling strategy consisted of 18 lessons. Every lesson included the pupils' worksheet and handouts. The pupils were provided with stationery sheets, 
Table 1. The number of words and questions of each story.

\begin{tabular}{|c|c|c|c|c|c|c|c|}
\hline \multirow[b]{2}{*}{ Story name } & \multirow[b]{2}{*}{ The topic } & \multirow[b]{2}{*}{ Words } & \multicolumn{5}{|c|}{ Questions } \\
\hline & & & Warm-up & $\begin{array}{l}\text { Storytelling } \\
\text { (Presentation) }\end{array}$ & $\begin{array}{l}\text { Halting the } \\
\text { Narration }\end{array}$ & $\begin{array}{l}\text { Finishing } \\
\text { the Story }\end{array}$ & $\begin{array}{c}\text { Stimulating } \\
\text { Questions }\end{array}$ \\
\hline Silence of a River & $\begin{array}{l}\text { The importance of water and methods of } \\
\text { preserving it. }\end{array}$ & 427 & 2 & 2 & 6 & 1 & 7 \\
\hline $\begin{array}{c}\text { Redha and the Wise man } \\
\text { of the Mountain }\end{array}$ & The importance of work & 757 & 2 & 2 & 5 & 2 & 7 \\
\hline I am Free & $\begin{array}{l}\text { The meaning of freedom and its playing in } \\
\text { our life }\end{array}$ & 336 & 1 & 2 & 6 & 3 & 6 \\
\hline Khawlabint Al-Azour & The role of women in society & 410 & 2 & 2 & 3 & 2 & 6 \\
\hline In the Forest & Preservation of the environment. & 541 & 4 & 3 & 5 & 3 & 9 \\
\hline A Small Lantern & The importance of will and its implication & 884 & 2 & 2 & 6 & 2 & 7 \\
\hline
\end{tabular}

colored cards and colored pens as part of the strategy. Five stories covering several themes were included in the strategy. These are described in the following Table 1.

All the stories were drafted by the researchers with the exception of "Khawlabint Al-Azour", which was borrowed with permission from the Ministry of Education. The strategy relied on sources such as, (Alex, 1988; Anderson, 2005; Dujmovic, 2006; Groce, 2001; Robinson, 2008; Rosen, 1986), and for formulating stimulating questions; (Ralston, 1993) and (AhSeo, 2007) for displaying the pictures and discussing them with pupils; (Morrow, 1986; Vygotsky, 1978) for acting and role-playing; (Vygotsky, 1978) and (Ball \& Stafford, 1986) for writing and drawing activities.

The researchers developed a new stage in this strategy which was not present in the previous sources, namely homework. The next day, the teacher discussed the strengths and weaknesses of the pupils' writing techniques including the idea structure, coherence, conjunctions and accuracy of expression. The duration of the strategy was implemented for 12 weeks over the course of 18 sessions. In order to determine the validity of the story writing skills test, ten jury members represented by college professors specializing in language teaching or language literature verified the face validity of the test and suggested certain changes which were subsequently taken into consideration before arriving to the final draft of the instrument. The jury members assessed the suitability of the stories for the pupils' level of comprehension, the relevance of the story questions in relation to the stated skills as depicted by the strategy, the balance between the test time and test item requirements, the sufficiency of the items to cover the identified skills, and the clarity of the test's instructions.

\subsection{Procedures}

Each experimental group session commenced with the preparation of the classroom by seating the learners in groups. Cooperative learning is an important feature associated with the teaching of the Arabic language. Each group con- 
sisted of four pupils. The pupils were provided with drawing pads, pencils, pens and colors.

Once the class started, the teacher activated the students' schemata about the topic. Then, the teacher stated the title and discussed what it represented, prior to relating the story. At this stage, the teacher used differences voice pitches while relating the story, as well as various stress and intonation patterns. The teacher imitated certain voices in the story. Sometimes, the teacher paused in order to focus on any specific point and ask pupils about their predictions and expectations of the upcoming events of the story. The teacher would then halt the narration between the plots in order to stimulate pupils' thoughts, discuss the story's organization, assess their understanding of the interdependence between events, speculate the ending, allow pupils to express their opinions about it, support and stimulate their imagination. Finally, the teacher resumed the narration until reaching the end of the story.

At the end of the session, the teacher discussed some stimulating questions and consolidated the learning of the participants on the basis of several activities, such as displaying a picture related to the story, role-playing, writing and drawing activities. In addition, homework was assigned in the case of each strategy.

The second session aimed to evaluate pupils' writing activities as part of the previously assigned homework. The teacher discussed the strengths and weaknesses of the pupils' writing techniques including the structure of ideas, cohesion, coherence and accuracy of expression. Spelling and grammatical mistakes would be recorded on the classroom board and discussed with the pupils.

In the control groups, the same six stories were given to the five teachers allocated to the groups. These teachers taught the pupils using the traditional methods prescribed in the teacher's guide. This was arranged so that the teachers allocated to the control groups would teach the story concurrently with the experimental groups. In the lesson, the teacher:

1) introduced the story.

2) discussed the story with the pupils (characters, events).

3) asked the pupils to read the story in silence.

4) gave the story to the pupils and asked them to answer some questions that based on the story at home.

5) corrected the pupils' answers in their handouts.

A story writing skills test was also created in order to assess the story writing skills among pupils before and after the implementation of the storytelling strategy. The pre-test was administered at the beginning of the first semester of the school year, whereas the post-test was administered at the end of the same semester. Pre- and post-tests play an essential role in the research design and are very important in order to check the effect of random samples on the selected measure (Robson, 2002). The differences among pupils recorded after the administration of the two tests could help evaluate the effectiveness of the treatment.

Based on the literature, the test included questions that asked the students to: 
1) formulate another appropriate introduction to the story.

2) create active roles for the characters in the story.

3) arrange and organize events according to their sequence and interdependence.

4) rewrite the arranged events of the story using coherence conjunctions.

5) build a suitable atmosphere for the course of events of the story (place/time).

6) build another appropriate ending for the story.

7) suggest a new title for the story.

8) describe the pictures in order to finalize the story.

9) use grammar and spelling.

10) use appropriate punctuation.

The test was piloted with 45 pupils from the same grade, but who were not part of the participants from previous studies. Only 15 pupils from each class were involved, the final number thus totaling to 45 pupils. Prior to the implementation of the test, the researchers briefed 3 teachers on the storytelling strategy over the course of 3 days using one of the stories. The researchers administered the pupils a pre-test in order to assess their story writing skills prior to the implementation of the strategy. As the strategy was being implemented by each of the teachers, the researchers observed and took field notes. Upon the finalization of the intervention stage, the researcher administered a post-test to the 45 pupils from the three classes.

Ten pupils out of the total number of 45 were selected to take the test in order to be able to assess the reliability thereof. One of the researchers marked 10 tests randomly and asked another marker to correct the same 10 tests without providing the second marker with the initial findings. Two weeks later, the researcher re-marked the same 10 test papers. The reliability of the test was evaluated using the Pearson product-moment correlation coefficient. The marking results are presented in the following table.

The results in Table 2 indicate that the reliability of the markings was $(0.99$, $0.95,0.93)$, respectively. These results implied that the test was highly reliable.

\section{Results and Discussion}

The aim of implementing the storytelling strategy is to examine the impact of storytelling on the development of story writing skills among the students participating in the experimental groups. The collected data was analyzed by calculating the mean and the T-test, as shown in the table below, which compares the performance of the experimental and control groups in terms of story writing.

Table 2. Reliability of the story writing skills test.

\begin{tabular}{cc} 
Marking & Reliability Coefficient \\
\hline First marker $\times$ first marker (fortnight interval) & 0.99 \\
First marker $\times$ second marker (no time difference) & 0.95 \\
First marker (fortnight interval) $\times$ second marker & 0.93
\end{tabular}


Table 3. Paired T-test results comparing the experimental and control groups' mean scores of story writing skills in the pre and post test.

\begin{tabular}{ccccccc}
\hline Group & Test & Mean & Std. Deviation & $\mathrm{T}$ & Sig. & Note \\
\hline Experimental & Pre & 20.64 & 10.34 & & & \\
$(\mathrm{~N}=120)$ & Post & 32.51 & 9.09 & 25.315 & $<0.001$ & Post \\
Control & Pre & 15.66 & 9.59 & & & \\
$(\mathrm{~N}=123)$ & Post & 13.77 & 9.44 & 4.421 & $<0.001$ & Pre \\
\hline
\end{tabular}

The results shown in Table 3 indicate that the mean score obtained by the experimental group in the post story writing test increased from 20.64 to 32.51 , thus indicating a statistically significant difference between the pre- and post-test results in this group. These results imply that the pupils' story writing skills improved after with the implementation of the storytelling strategy. On the other hand, there was a significant statistical difference between the pre- and post-test results in the control group in favor of the pre-test $(m=13.77)$.

The results also indicate that the storytelling strategy was useful and effective in the case of grade seven pupils working in the experimental group. The strategy seems to have positively affected the pupils' story writing abilities. This result is consistent with the findings of Perry (2008) who stated that pupils found storytelling to be a helpful resource for improving students' writing skills. Isabell et al. (2004) also reported that storytelling improved students' writing skills and encouraged their active participation. They looked forward to the lesson and enjoyed it throughout. The researchers of the current study observed that the pupils who participated in the control group and were taught using conventional methods appeared bored. The routine of the lesson left them unmotivated and uninterested for a long time over the course of their lessons.

\subsection{Type of School}

Education in Oman is provided by public and private schools. The researchers incorporated the school type in the study's design in order to examine the impact of storytelling on pupils' story writing skills in public and private schools. There are 20 male public schools and 12 female public schools in Salalah city where the study was conducted. In addition, there are 15 coeducation-based private schools. Four public schools (i.e. two male schools and two female schools) and two private schools were randomly selected. A total number of 120 pupils from both school types were involved in the experimental group. Due to the restricted availability of the grade seven classes in each private school, the researcher considered the grade seven class in the first private school as the control group and its counterpart class in other private schools as the experimental group. Table 4 shows mean and standard deviation across school type and method.

The means and standard deviation of the type of school and teaching method are shown in Table 4. On the basis, thereof it may be inferred that private schools $(\mathrm{m}=38.92)$ have a higher means than public schools. Furthermore, the 
Table 4. Mean and standard deviation across school type and method.

\begin{tabular}{ccccc}
\hline School Type & Method & N & Mean & Std. Deviation \\
\hline \multirow{3}{*}{ Private } & Normal Method & 17 & 24.26 & 7.87 \\
& Storytelling & 19 & 38.92 & 5.75 \\
& Total & 36 & 32.00 & 10.02 \\
\multirow{3}{*}{ Public } & Normal Method & 106 & 12.09 & 8.57 \\
& Storytelling & 101 & 31.31 & 9.12 \\
& Total & 207 & 21.47 & 13.06 \\
& Normal Method & 123 & 13.77 & 9.44 \\
& Storytelling & 120 & 32.51 & 9.09 \\
& Total & 243 & 23.03 & 13.18 \\
\hline
\end{tabular}

pupils in the experimental group who were exposed to the storytelling strategy $(\mathrm{m}=32.51)$ scored higher means than the pupils partaking in the control group. This indicates that pupils achieved better scores when the storytelling strategy was implemented, as opposed to the conventional method. In addition, the table shows the mean score of the experimental group $(\mathrm{m}=31.31)$ is higher than in the case of the control group $(m=12.09)$ showing statistically significant differences between the experimental and control groups in public schools in favor of the experimental groups in public schools. On the other hand, the table shows that the mean score of the experimental group $(m=38.92)$ is higher than in the case of its counterparts $(\mathrm{m}=24.26)$, showing statistically significant differences between the means of the experimental and control groups in favor of the experimental group in the private schools. This result conforms to the expectation outlined by (Al-Shehab, 2010), who posited that private schools in the Middle East provide better opportunities for learning and instructional development for learners, as opposed to public schools. These results could be attributed to a number of reasons. Firstly, private schools provide an enhanced educational environment for learners, such as smaller class sizes, which encourage pupils to interact with their teacher and which ultimately lead to a more comprehensive understanding of the instructional content (AlNaqa, 2000). Secondly, in the case of the private schools used in this study, there was only a grade seven class available, whereas each public school in the sample had at least 12 classes. Furthermore, the teacher's dedication to teaching in private schools is significantly higher than in the case of their counterparts in public schools. Thirdly, possibly as a result of their financial and educational background, the parents of pupils studying in private schools monitor their children's academic progress in a more stringent manner, as opposed to their counterparts in public schools.

The two-way ANOVA was used in order to investigate the effects of the school type and teaching method and the interaction between them. Table 5 reports that there are significant effects pertaining to the type of school in favor of private schools indicating values of F $1,239=40.603, p \leq 0.001$, respectively. The ANOVA also showed that there are significant effects to be identified in 
Table 5. Two-way ANOVA of pupils' performance in story writing according to school type and method.

\begin{tabular}{cccccc}
\hline Source & Sum of Square & df & Mean Square & F & Sig. \\
\hline School type & 2994.208 & 1 & 2994.208 & 40.603 & $<0.001$ \\
Teaching Method & 8773.025 & 1 & 8773.025 & 118.968 & $<0.001$ \\
School type $\times$ Teaching Method & 159.052 & 1 & 159.052 & 2.157 & 0.143 \\
Error & $17,624.574$ & 239 & 73.743 & & \\
\hline
\end{tabular}

Table 6. Mean and standard deviation across gender and method.

\begin{tabular}{ccccc}
\hline Gender & Method & $\mathrm{N}$ & Mean & Std. Deviation \\
\hline \multirow{3}{*}{ Female } & Normal Method & 62 & 16.06 & 10.10 \\
& Storytelling & 58 & 36.22 & 8.38 \\
& Total & 120 & 25.81 & 13.72 \\
\multirow{3}{*}{ Male } & Normal Method & 61 & 11.44 & 8.16 \\
& Storytelling & 62 & 29.04 & 8.39 \\
& Total & 123 & 20.31 & 12.08 \\
& Normal Method & 123 & 13.77 & 9.44 \\
& Storytelling & 120 & 32.51 & 9.09 \\
& Total & 243 & 23.03 & 13.18 \\
\hline
\end{tabular}

terms of the teaching method, which favor the storytelling strategy, $\mathrm{F}(1,234)=$ $118.968, p \leq 0.001$. The correlation between the type of school and the teaching method is insignificant.

The results of the study revealed that there was a statistically significant difference in the mean scores associated to the pupils' achievement between the two types of schools. The pupils in private schools achieved significantly higher story writing scores than the pupils in public schools. This was the case under both conditions. Both public and private schools in the experimental group scored significantly higher than their counterparts in the control group. However, the results indicated that the correlation between the type of schools and the teaching method is not statistically significant. This shows that the teaching method (storytelling strategy) did not influence the public and private schools in a different way.

\subsection{Gender}

Gender was also under scrutiny as a variable in this study. Data was analyzed by calculating the means, standard deviation and the two-way ANOVA. The two-way ANOVA was carried out in order to verify whether there is a significant interaction between teaching methods and gender. Table 6 presents mean and standard deviation across gender and method.

The mean scores and standard deviation of gender and teaching method are shown in Table 6. It presents that female $(\mathrm{m}=36.22)$ have higher mean in their 
Table 7. Two-way ANOVA test of pupils' performance in story writing according to gender and method.

\begin{tabular}{cccccc}
\hline Source & Sum of Square & df & Mean Square & F & Sig. \\
\hline Gender & 2115.171 & 1 & 2115.171 & 27.296 & $<0.001$ \\
Teaching method & $21,635.345$ & 1 & $21,635.345$ & 279.203 & $<0.001$ \\
Gender $\times$ Teaching method & 99.608 & 1 & 99.608 & 1.285 & 0.258 \\
Error & $18,520.027$ & 239 & 77.490 & & \\
\hline
\end{tabular}

marks than male. Also, the pupils in the experimental group who underwent the storytelling strategy $(m=32.513)$ scored higher means than the pupils of the control group. This signifies that the pupils achieved better scores using the storytelling than the normal method.

The table below shows the results of the ANOVA test indicating the students' performance in story writing according to gender and method.

Table 7 demonstrates the results of the two-way ANOVA that calculates the interaction between the variables. There is a statistically significant difference between the genders in favor of females, F 1, $239=27.296, p \leq 0.001$. The females achieved significantly higher scores in the story writing skills test than male pupils. This was also the case under both conditions. These achievement differences between males and females could be attributed to the notion that females possess a broader language lexicon as opposed to males, which allowed them to better express themselves when writing the stories. In addition, females have a stronger desire to acquire new knowledge, adopt new methods and interact with them. This result is in line with (Perry, 2008), who stated that females tend to perform better than males in writing assignments, whereas (Page, 2008) indicated that there are no significant differences between males and females in writing assignments. Unfortunately, there is a dearth of studies addressing this aspect of story writing.

Moreover, the ANOVA showed that there is a statistically significant difference between the teaching methods in favor of the storytelling strategy, F 1, 239 $=279.203, p \leq 0.001$. Nevertheless, the interaction between gender and the teaching method is insignificant which means that the teaching method (storytelling strategy) did not substantially differentiate between boys and girls.

\section{Conclusion}

The storytelling strategy employed in this study is an instructional strategy that provides learners with a visual guide to the basic story structure and the relationship between the elements of the story, which teachers may consider to be a useful resource during story writing lessons. The strategy is of special benefit when teachers endeavor to improve pupils' story writing skills. Learners often find it difficult to process and organize written information and when writing stories, they cannot always retrieve the information required for the development of the story. Generating relevant ideas for their stories is another dimension which they may regard as challenging where this strategy could be benefi- 
cial for learners.

Underdeveloped stories often have limited or incomplete outputs as a result of the limitation of pupils' story writing skills. When learners occasionally have good ideas for a piece of writing, they may not be able to properly formulate those ideas in writing. Therefore, they may become frustrated and stop writing before their stories are fully developed. The storytelling strategy provides learners with a visual plan, almost a graphic organizer, helping them to organize, link and remember information. When the storytelling strategy is used, writers are guided into exploring ideas and bringing a story into existence. The storytelling strategy is adaptable and easy to prepare. Teachers might find it valuable in their written composition lessons, especially in the case of those learners who have encountered difficulties in terms of story organization, content and output. It is recommended that decision makers in pre-tertiary education consider increasing the number of story writing lessons because learners would generally require more time to develop this skill under instruction. In written composition lessons, compositional aspects such as creativity, imagination, ideas, organization and the structure of the text should be given due consideration and a specific focus (Ministry of Education, 2004).

Policymakers, curricula professionals and practitioners would also find that employing the storytelling strategy in language curricula and instruction could entail benefits for their learners. They would be able to better understand the different aspects of storytelling and story writing that their learners need to focus on in order to improve their language skills. Curriculum development in this area would be particularly effective if learners' writing interests are taken into consideration. Curricula developers would also be able to share their ideas about the content of the language curriculum, so that new methods can be adopted in order to improve learners' story writing and increase the applicability of in-ser vice training courses.

Composing a narrative writing needs to focus on strategies that support learners to use richer vocabulary reservoir and organize their ideas coherently. Needless to mean that writing with limited vocabulary often demotes the sophistication of writing. In this study, the storytelling strategy did not result in improving lexical variety. Therefore, while storytelling is recommended for composition lessons, other strategies that focus on teaching lexical items should be promoted to facilitate such compositions. Coupling vocabulary with the storytelling strategy could be very valuable to learners to write more effective narrative compositions.

Writing is a process that encompasses planning, drafting revision and editing. Teachers should design activities that focus on the writing process and at the same time allow pupils adequate time to complete this process. However, asking pupils to go through all these steps in one writing session may not be realistic and could jeopardize learning the writing techniques in this strategy. On the other hand, scarce number of composition lessons, like the one reported in the study, is not a feasible solution as it would not help overcome the many writing 
difficulties that students face. It is advisable to brainstorm and prepare an outline first and then let the learners write the first draft on another day. This way, they will not feel the urgency to finish writing their story in a single session nor will they lose interest in writing it.

\section{References}

Abrahamson, C. (1998). Storytelling as a Pedagogical Too in Higher Education. http://www.findarticles.com

AhSeo, M. (2007). Storytelling with Picture Books. TESOL, 5, 41-56.

Aida, Y. (2007). Quantities and Qualitative Analyses of Students' Views on the Storytelling Project. Paper presented at the CJKP Proceedings Conference.

Alex, K. (1988). Storytelling, Its Wide-Raining Impact in the Classroom. Washington DC: Office of Educational Research and Improvement (ED).

Al-Hadidi, A. (1996). Children's Literature. Egypt: Egyptian Anglo Library.

Al-Mansour, N., \& Al-Shorman, R. (2011). The Effect of Teacher's Storytelling Aloud on the Reading Comprehension of Saudi Elementary Stage Students. Journal of King Saud University-Language and Translation, 23, 69-76.

AlNaqa (2000). Arabic Language Teaching in Public Education: Its Approaches and Techniques. V 2, 100-120.

Al-Shehab, A. J. (2010). The Impact of Private Sector Competition on Public Schooling in Kuwait: Some Socio-Educational Implications. ERIC, 131, 181-195.

Anderson, N. (2005). Elementary Children's Literature. London: Pearson Bassinets and Grundy.

Ball, B., \& Stafford, M. (1986). Synaesthetic Writing [microform]: A Six-Weeks Unit on Creative Writing/ Brenda Ball and Mary Ann Stafford. Washington, DC: Distributed by ERIC Clearinghouse.

Birkenkraha, M. (2014). Using Storytelling Methods to Improve Emotion, Motivation and Attitude of Students Writing Scientific Papers and Theses. IEEE Explore Digital Library. http://www.ieeexplore.ieee.org/abstract/document6921453/authors

Charlotte, L. (2001). Narrative in Institution. Oxford: Blackwell Publishing.

Chavis, V. (2009). Teaching Narrative Writing.

http://www.homeschooling.com/Arlide/B2-H

Davis, D. (2000). Writing as a Second Language: From Experience to Story to Prose. Atlanta, GA: August House.

Diawn, P. (2008). Case Study: The Influence of Storytelling as Prewriting Activity (in the Writing Process) on Narrative Writing in the No Child Left behind Learning Environment. Unpublished PhD Thesis, Philadelphia and Bala Cynwyd, PA: Saint Joseph's University.

Dinkson, D. (2001). Story Structure. Discourse Processes, 1, 12-21.

Distafano, L. (2007). Narrative Writing. UK: Collier High School.

Douglas, S. (2005). What Use Is Storytelling?

http://www.arts.gla.ac.uk/STELLA/STARN/journal/stories.htm

Dujmovic, M. (2006). Storytelling as a Method of EFL Teaching. Pergendira Journal, 3, 111-126.

Egan, K. (1987). Literacy and the Oral Foundation of Education. Harvard Educational Review, 57, 445-473. https://doi.org/10.17763/haer.57.4.3561260401mp2mg4 
Gallets, M. (2005). Storytelling and Story Reading: A Comparison of Effects and Children's Memory and Story Comprehension. MA Thesis. Tennessee: East Tennessee State University. http://dc.etsu.edu/cgi/viewcontent.cgi? article $=2180 \&$ context $=$ etd

Golden, J. (1984). Children's Concept of Story in Reading and Writing. The Reading Teacher, 37, 578-584.

Graham, S. (2006). Strategy Instruction and the Teaching of Writing: A Meta-Analysis. In C. A. MacArthur, S. Graham, \& J. Fitzgerald (Eds.), Handbook of Writing Research. New York: The Guilford Press.

Gregor, V. (1998). 42 Reasons for Teaching Storytelling. http://www.marilynikinsella.org

Groce, R. (2001). An Experiential Study of Elementary Teachers with Storytelling Process. PhD Thesis, College Station, TX: Texas A\&M University.

Hana, N. (2010). The Effectiveness of Using Storytelling Technique to Develop EFL Listening Skills of The Primary Stage Students. Unpublished M.A. Thesis, Egypt: Mansoura University.

Hanoora, A. (1999). Children's Literature and Their Libraries. Kuwait: Al-Falah Library.

Hillocks, G. (1995). Teaching Writing as Reflective Practice. New York: Columbia University Press.

Isabell, R., Sobool, J., Lindauer, L., \& Lowrance, A. (2004). The Effect of Storytelling and Story Reading on the Oral Language Complexity and Story Comprehension of Young Children. Early Childhood Education Journal, 23, 157-163.

https://doi.org/10.1023/B:ECEJ.0000048967.94189.a3

Issa, F. (2007). Children's Literature. Jordon: New Books World Press.

Koki, S. (1998). Storytelling: The Heart and Soul of Education. Pacific Resources for Education and Learning.

http://www.prel.org/products/products/storytelling.pdf

Lipman, M. (1999). Thinking in Education. Cambridge: Cambridge University Press.

Meher, V. (1995). “Tell Me a Story”: Using Children’s Oral Culture in a Preschool Setting. Montessori Life, 7, 19-21. (ERIC Document Reproduction Service No. EJ508914)

Mello, R. (2001). The Power of Storytelling: How Oral Narrative Influences Children's Relationships in Classrooms. International Journal of Education \& the Arts, 2.

Meyer, J., \& Bogdan, G. (2001). Our “First Education”. In L. Berry, A Pilgrimage of Color. Paper presented at the National Conference, Social Science Monograph Series. Morehead, KY: Morehead State University.

Migawer (2001). Teaching of Arabic Language at Secondary Stage (Its Basis and Educational Applications). Egypt: Dar-Alfiker.

Ministry of Education (2004). Quality Education in Oman. Retrieved from Muscat.

Ministry of Education (2009). The First Educational Forum for Development and Linguistic Performance. Education Journal, Muscat.

Morrow, L. (1986). Effects of Structural Guidance in Story Retelling on Children's Dictation of Original Stories. Journal of Literacy Research, 18, 135-152.

https://doi.org/10.1080/10862968609547561

Page, R. (2008). Variation in Storytelling Style amongst New Zealand School Children. Narrative Inquiry, 18, 152-179. https://doi.org/10.1075/ni.18.1.08pag

Patterson, M. (1999). The Art Form of Painting Pictures with Your Tongue. http://www.hollowtop.com/storytelling.htm

Perry, K. (2008). From Storytelling to Writing: Transforming Literacy Practices among 
Sudanese Refuges. Journal of Literacy Research, 40, 317-358.

https://doi.org/10.1080/10862960802502196

Pfeiffer, S., \& Boles, C. (2008). Story Grammar Wiki Info. La 3314 Web Quests, IU Press.

Ralston, M. (1993). An Exchange of Gifts: A Storyteller's Handbook. Markham, ON: Pippin Publishing Limited.

Robinson, E. (2008). The Educational Benefits of Storytelling. http://www.helium.com/items/842112-the-educational-benefits-of-storytelling

Robson, C. (2002). Real World Research: A Resource for Social Scientists and Practitioner-Researchers (2nd ed.). UK: Blackwell.

Rosen, H. (1986). The Importance of Story. Language Arts, 63, 226-227. (ERIC Document Reproduction Service No. EJ 331133)

Schnee, A. (2010). Student Writing Performance: Identifying the Effects When Combining Planning and Revising Instructional Strategies. PhD Thesis, Lincoln, NE: University of Nebraska-Lincoln.

Shahata, H. (2000). Arabic Language Teaching between Theory and Practice. Egypt: The Lebanese Arab Dar.

Sisserson, K., Manning, C., Kenpler, A., \& Jolliffe, D. (2002). Authentic Intellectual Achievement in Writing. The English Journal, 91, 63-69. https://doi.org/10.2307/821818

Spivey, N. (1989). Constructing Constructivism Reading Research in the United States. Occasional Paper, No. 12, Carnegie Mellon.

Sue, T. (2007). Narrative Story Writing. http://www.narrative.org

Thomas, P. (2000). The Struggle Itself: Teaching Writing as We Know We Should. The English Journal, 90, 39-45. https://doi.org/10.2307/821729

Vygotsky, L. (1978). Mind in Society the Development of Higher Psychological Processes. Cambridge, MA: Harvard University Press.

Yang, Y. T. C., \& Wu, W. C. I. (2012). Digital Storytelling for Enhancing Student Academic Achievement, Critical Thinking and Learning Motivation: A Year-Long Experimental Study. Computers \& Education, 59, 339-352.

Zabel, M. (1991). Storytelling, Myths, and Folk Tales: Strategies for Multicultural Inclusion. Preventing School Failure: Alternative Education for Children and Youth, 36, 3234. 


\section{Appendix}

Story writing skills test

Task (1)

Read the following story and then write an expected ending in two lines:

Ahmed is a student in the seventh grade. During the summer holiday, he visited Salalah. When he arrived at the beach, he went swimming. Some people were sitting on the beach enjoying the beautiful view of the sea. Ahmed wanted to have fun with these people and he shouted loudly: "Help! Help! I'm drowning!" Several people swam to help him. When they approached him, he laughed: "Ha...Ha...Ha...I'm only kidding!" They swam back, furious. After a short while, Ahmed repeated the same trick and several people spontaneously swam to help him, but he laughed just like the first time. They returned again and became even angrier with him. Then Ahmed felt tired and he could not get out of the sea

Task (2)

Fill in the gaps with the appropriate time and place elements in the story.

Once upon a time, when Omar was walking he saw some children playing. The children saw him coming from his house they all ran away except one. Omar asked the boy: "Why didn't you run away with your friends?" The boy said "the road is not so narrow for you to give me room and I have not done anything wrong to fear you". Omar felt happy at this boy's bravery and boldness.

Task (3)

Write a new introduction for this story in no more than two lines.

The eagle carried the turtle with its strong claws and threw it in the sea. The eagle watched it drown in the sea. As soon as the turtle touched the water, its head and legs popped out of the shell and it laughed victoriously, and said: "the water is my home and you brought me back. Thank you". Then it dived into the water away from the surface leaving behind it the sad eagle.

\section{Task (4)}

Rearrange the following sentences in terms of the relationships between them using the appropriate coherence tools.

Called his children to encircle him.

'Bring me a set of sticks from that tree,' he to one of his sons.

Once upon a time, an old wise man became very old and felt he was about to pass away.

The wise old man said, "Dear sons you are like this bunch of sticks. If you are together you are strong against your enemies but if you separate, they will get 
you.

They dismantled the sticks.

The son gave his father the set.

The sons tried to break the set together.

The father said to his sons: "Now, try to break the sticks one by one" and the sons broke them easily.

They failed to break it.

The father said to his sons "try to separate the sticks".

Task (5)

Create a new title for the previous story.

Task (6)

Read the following text and answer the questions:

Once upon a time a teacher had an intelligent student. He loved him a lot, and the student loved his teacher, so much so that one day the teacher sent his student to the market and asked him to buy him the best piece of meat the students go and baught a tongue the following day the teacher sent the student to the market and asked him to buy the worst piece of meat then the student went and also baught a tongue the teacher exclaimed and said why did you buy a tongue in both instances the student replied: teacher I does not find in a man's body better or worse than the tongue. If it lies it hurt people and makes Allah angry if it tells the truth it benifits people and pleases Allah

Correct the underlined words grammatically.

Correct the spelling of the words in bold.

Place the right punctuation marks in the correct positions in the previous story. 
Task (7)

Complete the following story in relation to the introduction and the ending:

Once upon a time, Salem returned home in the evening with profound sorrow on his face. His father noticed this and he asked him about the reason

My friends and I quickly rushed him to the hospital. He is still there in a coma.

Task (8)

Write a complete story about these pictures (characters and events).


5

6

7

8

The exam is finished Thank you 
Submit or recommend next manuscript to SCIRP and we will provide best service for you:

Accepting pre-submission inquiries through Email, Facebook, LinkedIn, Twitter, etc. A wide selection of journals (inclusive of 9 subjects, more than 200 journals)

Providing 24-hour high-quality service

User-friendly online submission system

Fair and swift peer-review system

Efficient typesetting and proofreading procedure

Display of the result of downloads and visits, as well as the number of cited articles Maximum dissemination of your research work

Submit your manuscript at: http://papersubmission.scirp.org/

Or contact ojml@scirp.org 